\title{
Sonographic Assessment of Ovarian Follicular Dynamics during Breeding and Non-Breeding Season in Gaddi Goats
}

\section{Amit Sharma ${ }^{*}$ and Pankaj Sood ${ }^{2}$}

${ }^{1}$ Department of Veterinary Gynaecology and Obstetrics, CSK Himachal Pradesh Krishi Vishvavidyalya, Palampur, Himachal Pradesh 176062, India; ${ }^{2}$ Department of Veterinary Clinical Complex, CSK Himachal Pradesh Krishi Vishvavidyalya, Palampur, Himachal Pradesh 176062, India.

Abstract | The present study evaluated the seasonal differences in ovarian follicular dynamics in Gaddi goats. Transrectal ultrasonographic ovarian examinations were carried out during a full estrous cycle in breeding (B; January-February, $n=7$ ) and 21 days in non-breeding (NB; May-June, $n=11$ ) seasons. Blood sampling on alternate days was done during both the seasons for serum progesterone (P4) estimations. Follicular growth was characterized by presence of three to five numbers of follicular waves in both seasons. Significantly higher $(\mathrm{P}<0.01)$ number of follicular waves $(4.0 \pm 0.21$ versus $3.18 \pm 0.12)$, number of follicles at wave emergence during second $(2.85 \pm 0.26$ versus $1.77 \pm 0.14 ; \mathrm{P}<0.01)$ and third wave $(2.57 \pm 0.2$ versus $2.0 \pm 0.16 ; \mathrm{P}<0.05)$, along with shorter persistence of dominant follicle (DF, $9.25 \pm 0.45$ versus $12.02 \pm 0.44, \mathrm{P}<0.001)$ and early attainment of DF during first three waves was observed during $\mathrm{B}$ compared to the NB season. Whereas, significantly higher maximum diameter of $\mathrm{DF}(7.66 \pm 0.10$ versus $7.11 \pm 0.14 \mathrm{~mm}, \mathrm{P}<0.05)$ and longer Inter wave interval (IWI) between $2^{\text {nd }}$ and $3^{\text {rd }}$ wave $(5.81 \pm 0.46$ versus $4.28 \pm 0.28$ days) were observed during NB season. Average mean $\mathrm{P} 4$ concentration was $0.30 \pm 0.04 \mathrm{ng} / \mathrm{ml}$ throughout the period of observation during NB whereas, peak P4 concentration of $11.89 \pm 1.55 \mathrm{ng} / \mathrm{ml}$ was observed at Day 14 of estrous cycle during B season. Significant difference between average daily counts of small, medium along with daily total number of visible follicles were observed during B season. In conclusion, ovarian follicular growth in Gaddi goats during B and NB season is characterized by wave like pattern and exhibited the seasonal differences.

Editor | Muhammad Abubakar, National Veterinary Laboratories, Park Road, Islamabad, Pakistan.

Received | June 09, 2020; Accepted | July 29, 2020; Published | October 16, 2020

*Correspondence | Amit Sharma, Department of Veterinary Gynaecology and Obstetrics, CSK Himachal Pradesh Krishi Vishvavidyalya, Palampur, Himachal Pradesh 176062, India; Email: vet50amy@gmail.com

Citation | Sharma, A. and P. Sood. 2020. Sonographic assessment of ovarian follicular dynamics during breeding and non-breeding season in Gaddi goats. Veterinary Sciences: Research and Reviews, 6(2): 124-131.

DOI | http://dx.doi.org/10.17582/journal.vsrr/2020.6.2.124.131

Keywords | Follicular dynamics, Gaddi goats, Progesterone, Season, Ultrasonography

\section{Introduction}

G oats are important livestock species of India. T Goat husbandry plays an important role in the livelihood of a large proportion of small/ marginal farmers, landless labourers and sustain the rural economy, with multi-facet utility for chevon, milk, skins and manure. There is rich biodiversity among the indigenous goat in India, evidenced by more than
20 listed breeds of goat. The goat contributes around $27.8 \%$ of total livestock population in India (148.88 million; 20 ${ }^{\text {th }}$ Livestock census, 2019). Gaddi is well recognized breed of goat found in Himachal Pradesh, India. A progressively declining cattle population in the state accentuates goat rearing under the small household system.

Goat is considered to be seasonally polyestrous and 
short day breeder. The annual change in the day length is the main environmental factor that affects seasonal breeding in goats (Fatet et al., 2011), although temperature and breed differences has also been associated with reproductive activity (Farsi et al., 2018).

The ovarian follicular dynamics and endocrine investigation are important yardsticks delineating the effects of environment on breeding and conception. Ultrasonography is simple, non-invasive and a reliable technique widely utilized in small ruminants (Gonzalez de Bulnes et al., 1999). Ultrasound guided follicular dynamics have been studied by various researchers (Cruz et al., 2005; Medan et al., 2005; Simoes et al., 2006; Nogueira et al., 2015; Sharma and Sood, 2019) during B and NB season at different latitudes and in different breeds of goats. Ultrasonographic studies revealed that the follicle grows to a diameter of $\geq 5 \mathrm{~mm}$ with average growth rate of $0.8-1.1 \mathrm{~mm}$ per day throughout the estrous cycle (Medan et al., 2005; Simoes et al., 2006) and anestrous periods (Cruz et al., 2005; Nogueira et al., 2015). Follicular growth occurs in a wave like manner throughout the estrous cycle irrespective of season which is characterized by sequence of three gonadotropin-dependent events in follicular growth viz. recruitment, selection and dominance (Ginther and Kot, 1994; Mohammadi et al., 2010; Nogueira et al., 2015). Also, temporal relationships between follicular dynamics and hormonal profiles are well established in goats (Medan et al., 2005; Vasquez et al., 2010).

The follicular dynamics alongwith endocrine profiling in goats during both the seasons have been reported in limited number of studies (Boer et al., 2015; Saanen et al., 2020). Hence, present study reports the comparative follicular growth characteristics along with progesterone profiling during $\mathrm{NB}$ and subsequent B season in Gaddi goats.

\section{Materials and Methods}

\section{Selection of animals and period of investigation}

Ultrasonography guided follicular dynamics study was done in total eighteen adult, healthy and non pregnant Gaddi does. Average (mean \pm SEM) age and bodyweight of the does during the period of investigation were $3.74 \pm 0.28$ years, $24.27 \pm 0.70 \mathrm{~kg}$ and $4.52 \pm 0.39$ years, $27.07 \pm 1.03 \mathrm{~kg}$, respectively during NB $(n=11)$ and B $(n=7)$ season. Significant difference $(\mathrm{P}<0.05)$ in body weights during $\mathrm{NB}$ and $B$ were observed in the Gaddi goats.

\section{Location, bousing and feeding of animals}

All the does were maintained at University Livestock Farm of CSK Himachal Pradesh Krishi Vishvavidyalya, Palampur $\left(32.6^{\circ} \mathrm{N}, 76.3^{\circ} \mathrm{E}\right.$, altitude $1290.8 \mathrm{~m})$. All animals were subjected to grazing for five hours and remained under confinement in a shed where they were fed as per the standards of Indian Council of Agricultural Research (ICAR, 2013) with round the clock access to the clean drinking water.

\section{Ultrasonography}

Ultrasonography was performed using 7.5 $\mathrm{MHz}$ linear array transducer (Exago, ECM France) as per defined technique (Ginther and Kot, 1994; Medan et al., 2003; Nogueira et al., 2015). All ultrasound examinations of the ovaries were done by a single operator. All follicles $\geq 3 \mathrm{~mm}$ in diameter and corpora lutea were measured using electronic callipers and ovarian sketches were drawn. Different follicular wave parameters were studied and defined as per standard definitions (Ginther and Kot, 1994). A follicular wave was defined as one or more antral follicles growing from 3 to $\geq 5 \mathrm{~mm}$ in diameter before subsequently regressing and being no longer detectable. The follicles were classified as small (3.0 to $<3.5 \mathrm{~mm}$ ), medium $(\geq 3.5 \mathrm{~mm}$ to $<5 \mathrm{~mm})$ and large $(\geq 5 \mathrm{~mm})$. The first wave at the beginning was defined as Wave 1 and the following waves were numbered sequentially. The day of emergence (DE) of follicles was identified as the day on which the dominant follicle within a given follicular wave was retrospectively first observed to be $\geq 3 \mathrm{~mm}$ in diameter. The end of a follicular wave was recorded when dominant follicle(s) associated with a follicular wave could no longer be identified. Individual follicles emerging within a $48 \mathrm{~h}$ period of the day of emergence of the dominant follicle were regarded as belonging to the same follicular wave. The duration of a follicular wave was defined as the interval between the day of emergence and the day the follicular components of the said follicular wave could no longer be identified. The inter wave interval (IWI) was recorded as the number of days in between the start of two sequential follicular waves. Follicular growth rate $(\mathrm{mm} /$ day) was the maximum diameter after emergence divided by number of days taken to achieve it. The day of maximum follicular diameter (DM) was the first day in each wave when dominant follicles attained maximum diameter. The regression 
rate was calculated by diameter of follicle at last day of static phase by number of days taken to its disappearance.

\section{Synchronization}

Reproductive cyclicity was ascertained on basis of transrectal ovarian ultrasonography and progesterone (P4) estimation. Estrus was synchronized with double injections of Cloprostenol (187.5 $\mu \mathrm{g})$ eleven days apart during the B season. Ultrasonography was carried out once daily once after administration of the last dose of Cloprostenol to detect ovulation with examinations continuing till the next ovulation. However, during NB season ultrasonography was initiated randomly and lasted for one month so that the cut-off period of 21 days was retrospectively analyzed to consider the initiation of a follicular wave and further evaluated for wave characteristics.

\section{Ethical considerations and hormonal analysis}

All the experiments were carried out after the approval of ethical committee of the institute and the principles under Declaration of Helsinki were also taken into consideration. Blood samples were collected every alternate day in the B and NB season. The samples were obtained by jugular venipuncture in a $5.0 \mathrm{ml}$ sterile syringe. Serum was isolated and frozen $\left(-20^{\circ} \mathrm{C}\right)$ until assayed for $\mathrm{P} 4$ by Chemiluminiscence analyzer using Acculite Progesterone kit (Lilac Medicare Ltd., India). Progesterone concentration and ovarian status were correlated at different day of observation or estrous cycle depending upon the presence or absence of estrous cycle (Menchacha and Rubianes, 2002).

\section{Statistical analysis}

The data obtained were analysed using package $\mathrm{R}$ (ver 3.4.3). Interactions included in the Analysis of Variance (ANOVA) model were between the effects of the breeding season and the order in which follicular waves (first, second, third, fourth or fifth wave) recorded during the period of observation were tested using General Linear Model of one way ANOVA based on Fisher's Least Significant Difference method. The significant values in the ANOVA were further tested through Duncan analysis. Results are presented as mean \pm SEM and differences were considered significant when $\mathrm{P}<0.05$.

\section{Results and Discussions}

Average (mean \pm SEM) light: dark $h$ in a day during the month of May and June (NB season) and January and February (B season) were 13.88 $\pm 0.006: 10.12 \pm 0.006$, 13.76 $\pm 0.004: 10.24 \pm 0.004,10.27 \pm 0.01: 13.73 \pm 0.001$ and 10.88 $\pm 0.004: \quad 13.12 \pm 0.004$, respectively. Significant difference $(\mathrm{P}<0.01)$ between the light and dark hours during NB and $\mathrm{B}$ season were recorded in present study. Ultrasonography revealed that follicular development occurred in wave like manner irrespective of the season. Majority of goats $(9 / 11 ; 81.8$ per cent) exhibited 3 follicular waves during NB season whereas 71.4 per cent (5/7) goats exhibited 4 wave pattern during the $B$ season. Overall data during NB and $B$ season, the average number of follicular waves were significantly higher $(\mathrm{P}<0.01)$ during $\mathrm{B}$ season compared to $\mathrm{NB}$ season $(4.0 \pm 0.21$ versus $3.18 \pm 0.12)$. Our findings are in contrast to earlier observations (Nogueira et al., 2015, 4.8 \pm 0.1 versus $4.1 \pm 0.1$ ) and Dogan et al., $2020(4.95 \pm 0.27$ versus $4.84 \pm 1.58)$ who reported higher number of waves during NB than breeding season. Various researchers' have examined follicular dynamics during the estrous cycle of goats and reported the occurrence of two to six follicular waves during an estrous cycle, with an average of four waves per cycle (Ginther and Kot, 1994; de Castro et al., 1999; Menchaca and Rubianes, 2002; Medan et al., 2005; Simoes et al., 2006; Mohammadi et al., 2010; Nogueira et al., 2015; Dogan et al., 2020). Variations in the number of waves could be related to breed, age, environment and nutrition as well as seasonal differences in the frequency and amplitiude of the gonadotropic hormones Hence, it could be concluded from the present study that Gaddi goats have wavelike pattern of ovarian follicular growth irrespective of season, as reported earlier in cyclic (Ginther and Kot, 1994; de Castro et al., 1999; Menchaca and Rubianes, 2002; Medan et al., 2005; Simoes et al., 2006; Mohammadi et al., 2010; Nogueira et al., 2015; Dogan et al., 2020) and anestrus (Cruz et al., 2005; Nogueira et al., 2015; Dogan et al.,2020) goats. During B season last wave of the estrous cycle was ovulatory as depicted by disappearance of preovulatory follicle and visualization of increased heterogenous echogenicity in its site characterizing corpus haemorrhagicum (Gonzalez-Bulnes et al., 2004).

Perusal of the Table 1 suggests insignificant variation in the day of emergence (DE) of respective waves during $\mathrm{B}$ and $\mathrm{NB}$ season except the third wave of $B$ versus $\mathrm{NB}$ season $(9.28 \pm 0.47$ versus $11.36 \pm 0.50$; $\mathrm{P}<0.05)$. Significantly higher number of follicles at wave emergence were recorded in second $(2.85 \pm 0.26$ 


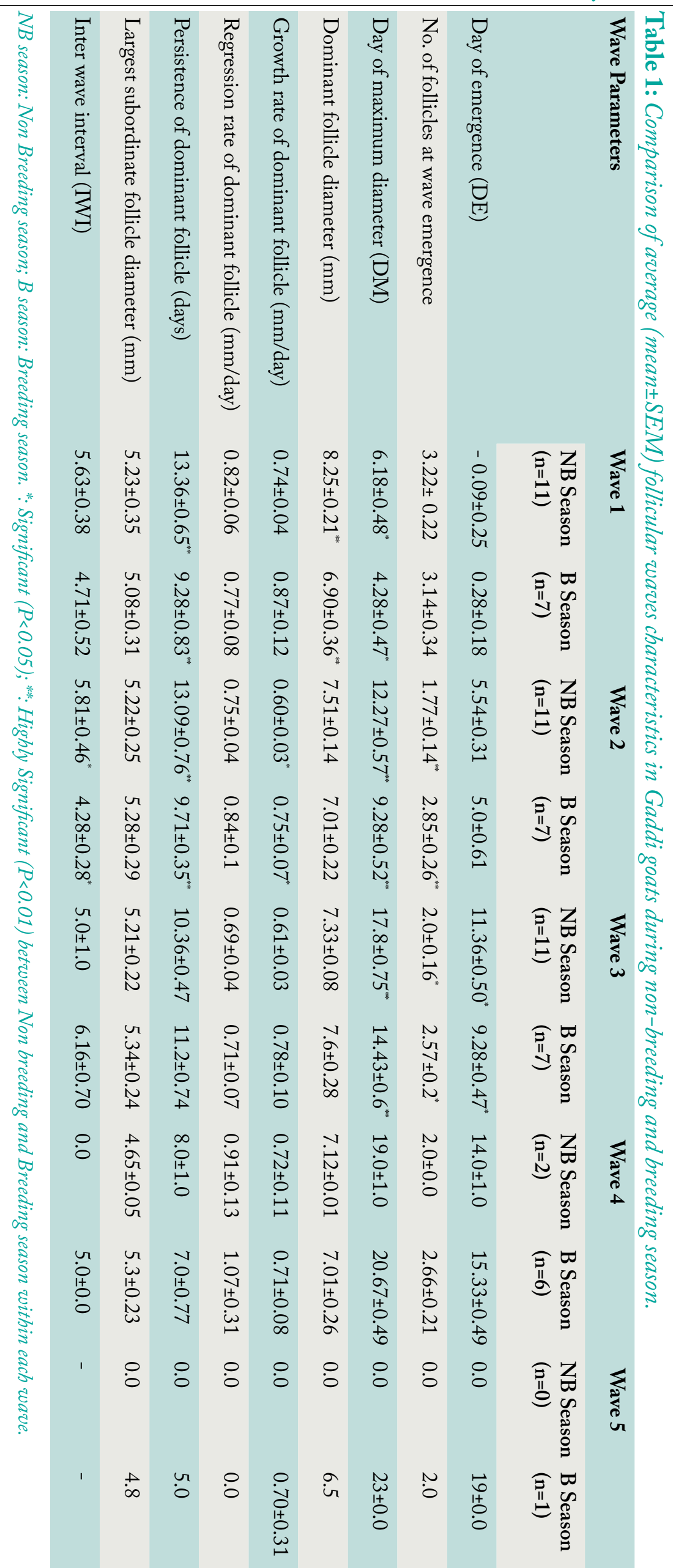


versus $1.77 \pm 0.14 ; \mathrm{P}<0.01)$ and third wave $(2.57 \pm 0.2$ versus $2.0 \pm 0.16 ; \mathrm{P}<0.05)$, respectively during $\mathrm{B}$ compared to the NB season. Researchers (de Castro et al., 1999; Menchaca and Rubianes, 2002) have established the relationship of mid luteal phase estradiol, P4 concentration and the number of follicular waves. They suggested that estradiol concentration declined earlier in the four wave than three wave goats and this early decrease of estradiol is hypothesized to cause early FSH rebound yielding in the emergence of second follicular wave. Whereas, in three wave animals the wave 2 emergence was delayed until the decrease of estradiol concentration, which occurred later (Rubianes and Menchaca, 2003). During $\mathrm{B}$ season endocrine and paracrine regulation of gonadotropins is well established justifying their role in follicular development (Hunter et al., 2004). In brief, the variation in the gonadotropin secretion would explain the differences in follicular dynamics between B and NB season (Bartlewski et al., 1999).

Significantly shorter persistence of dominant follicle in wave 1 (DF; $9.28 \pm 0.83$ versus $13.36 \pm 0.6, \mathrm{P}<0.01$ ), wave $2 \mathrm{DF}(9.71 \pm 0.35$ versus $13.09 \pm 0.76, \mathrm{P}<0.01)$ were observed during $\mathrm{B}$ than $\mathrm{NB}$ season (Table 1 ). Data combined separately for all the waves revealed significantly shorter persistence of DF during $\mathrm{B}$ than $\mathrm{NB}$ season $(9.25 \pm 0.45$ versus $12.02 \pm 0.44, \mathrm{P}<0.001)$. Similarly, shorter persistence of DF was observed in wave $4(71.4 \%)$ and wave $5(14.2 \%)$, respectively during breeding season in Gaddi goats. Both of these waves were ovulatory as indicated by onset of luteolysis and LH surge which spurs the growth of follicles (Ginther and Kot, 1994; de Castro et al., 1999; Nogueira et al., 2015).

Barring the average diameter of wave $1 \mathrm{DF}(6.90 \pm 0.36$ $\mathrm{mm}$ ) during $\mathrm{B}$ season that was significantly smaller than average diameter of corresponding wave $(8.25 \pm 0.21$ $\mathrm{mm}$ ) during $\mathrm{NB}$ season, the average diameter of DF of wave 2 and 3 (considering the presence of at least 3 waves during both seasons) were similar during NB and $\mathrm{B}$ season. However, combining the data for all waves, though separately for $\mathrm{NB}$ and $\mathrm{B}$ season, the diameter of DF was smaller during $\mathrm{B}$ than $\mathrm{NB}$ season (7.11 \pm 0.14 versus $7.66 \pm 0.10 \mathrm{~mm} ; \mathrm{P}<0.05)$. The latter justifies the lower average size of DF in $\mathrm{B}$ than NB season. The maximum diameter of $\mathrm{DF}$ during the $\mathrm{B}$ season was attained earlier compared to NB season during first three waves which could be explained by the fact that majority of animals were following four wave pattern (71.4 per cent) in contrary to three waves pattern (81.6 per cent) during NB season.

The overall average growth rate of DF was significantly increased during $B$ than $\mathrm{NB}$ season $(0.79 \pm 0.04$ versus $0.65 \pm 0.03, \mathrm{P}<0.05)$. Insignificant differences $(\mathrm{P}>0.05)$ between the growth and regression rates of the DF during different waves, except for wave 2 (growth rate; $0.75 \pm 0.07$ versus $0.60 \pm 0.03, \mathrm{P}<0.05$ ) during $\mathrm{B}$ and $\mathrm{NB}$ season were observed in present study. Both, maximum diameter and growth rate of $\mathrm{DF}$ are governed by the varying concentration of $\mathrm{LH}$ (Ginther and Kot, 1994; Gonzalez de Bulnes et al., 1999; de Castro et al., 1999; Schwarz and Wierzchos, 2000; Rubianes and Menchaca, 2003; Medan et al., 2003; Simoes et al., 2006; Nogueira et al., 2015). In cycling animals, simulating to goats during B and NB season, increasing concentration of $\mathrm{P} 4$ after ovulation is one reason which limits the $\mathrm{LH}$ pulse frequency (Nogueira et al., 2015). Our observation pertaining to higher growth rates (around $1 \mathrm{~mm} /$ day) during $\mathrm{B}$ are in consonance to earlier reports (Ginther and Kot, 1994; Gonzalez de Bulnes et al., 1999; de Castro et al., 1999; Schwarz and Wierzchos, 2000; Rubianes and Menchaca, 2003; Medan et al., 2003; Simoes et al., 2006; Nogueira et al., 2015; Dogan et al., 2020), than NB season (Nogueira et al., 2015; Dogan et al., 2020). Increased secretion of the LH during B season could be hypothesized for faster follicular growth rates compared to during NB season (Ginther and Kot, 1994; Nogueira et al., 2015).

Inter wave interval (IWI) between wave 2 and 3 was significantly longer (5.81 \pm 0.46 days) in NB compared to $B(4.28 \pm 0.28$ days) season (Table 1$)$. Combining the IWI for different waves revealed marginally longer IWI during NB (5.66 \pm 0.2 days) than B $(4.90 \pm 0.31$ days) season. Insignificant differences in IWI between wave 3 and wave 4 during the $B$ season have also been observed earlier (de Castro et al., 1999; Menchaca and Rubianes, 2002; Simoes et al., 2006). Such differences have been proposed to occur due to endocrine variations during the estrous cycle, especially effect of $\mathrm{P} 4$ concentration on the follicular development. High P4 concentration terminates a wave earlier causing an emergence of next wave that ultimately reduces the follicular wave emergence interval. Progesterone inhibits follicular development by suppressing the LH pulse frequency. Longer IWI between ovulatory and its immediately preceding wave (6.16 \pm 0.70 days) during $B$ season than any other two successive waves in NB season in 
present study, corroborates to observations of Simoes et al. (2006). This supports the concept of indirect P4 action on follicular turnover and the fundamental role of natural luteolysis in providing an opportunity for final follicular maturation and ovulation of the DF of the ovulatory wave.

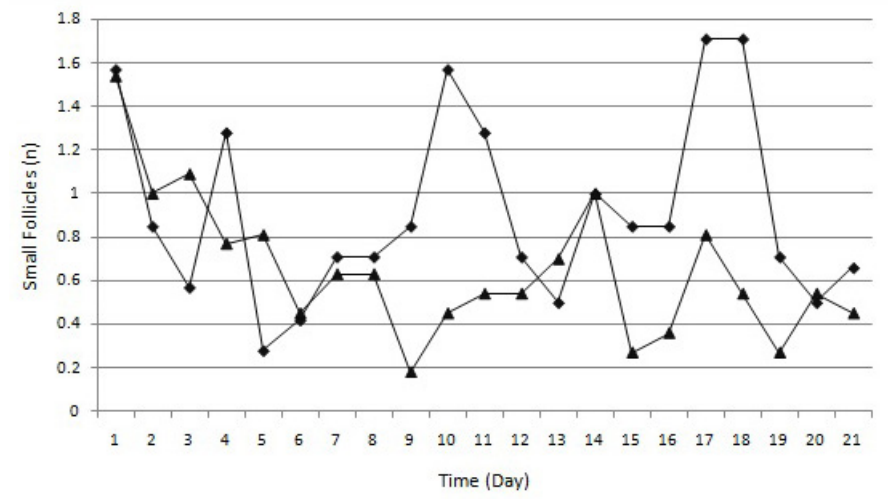

Figure 1a: Daily changes in the number of small follicles $(3 \mathrm{~mm}$ $<3.5 \mathrm{~mm}$ diameter) for 21 days in Gaddi goats during the breeding (घ) and non-breeding seasons ( $\mathbf{\Delta}$ ).

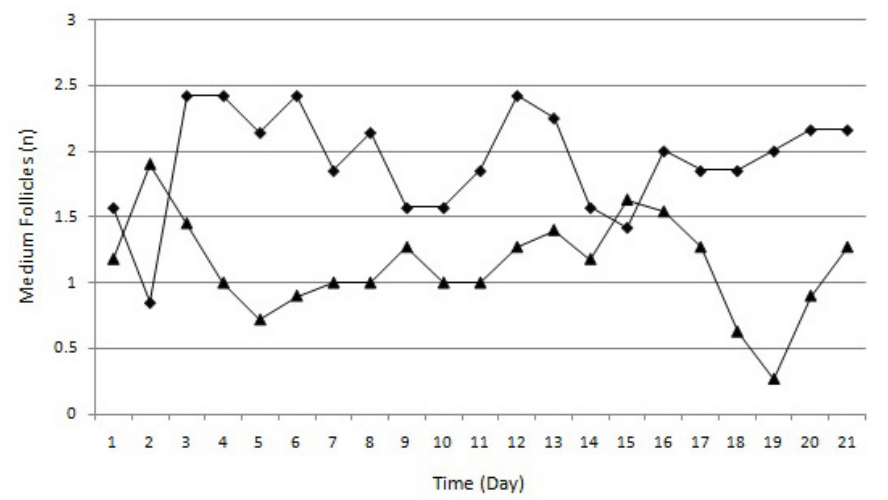

Figure 1b: Daily changes in the number of medium follicles $(\geq 3.5$ $m m$ to $<5.0$ mmdiameter) for 21 days in Gaddi goats during the breeding ( $\mathbf{-}$ ) and non-breeding seasons ( $\mathbf{\Delta})$.

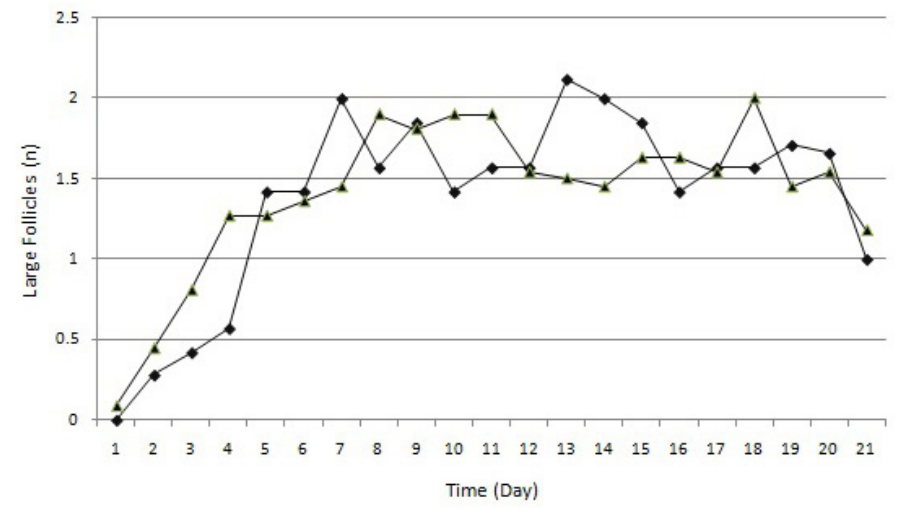

Figure 1c: Daily changes in the number of large follicles $(\geq 5.0 \mathrm{~mm}$ diameter) for 21 days in Gaddi goats during the breeding (口) and non-breeding seasons ( $\mathbf{\Delta})$.

Perusal of (Figure 1a-d) indicates significantly higher daily number of small and medium sized follicles along with the average daily total number of visible follicles
$(1.12 \pm 0.20$ versus $0.63 \pm 0.06, \mathrm{P}<0.05 ; 2.59 \pm 0.69$ versus $1.14 \pm 0.07, \mathrm{P}<0.01$ and $5.50 \pm 0.55$ versus $3.15 \pm 0.67, \mathrm{P}<0.05)$, respectively. Significantly higher daily number of small and medium sized follicles along with the average daily total number of visible follicles during $B$ season (Figure $1 \mathrm{a}-\mathrm{d}$ ) is suggestive of pronounced ovarian activity during the $\mathrm{B}$ season in agreement to the earlier observations (Ginther and Kot, 1994; Medan et al., 2003, 2005; Simoes et al., 2006; Mohammadi et al., 2010; Nogueira et al., 2015; Dogan et al., 2020). High plasma P4 concentrations during the estrous cycle suppress the basal secretion of $\mathrm{LH}$, which is responsible for changes in antral follicle maturation until deviation. The dependence of the development of large antral follicles on FSH results in a decrease in number of follicles leading to a reduced number of follicles during $\mathrm{NB}$ season (Fatet et al., 2011).

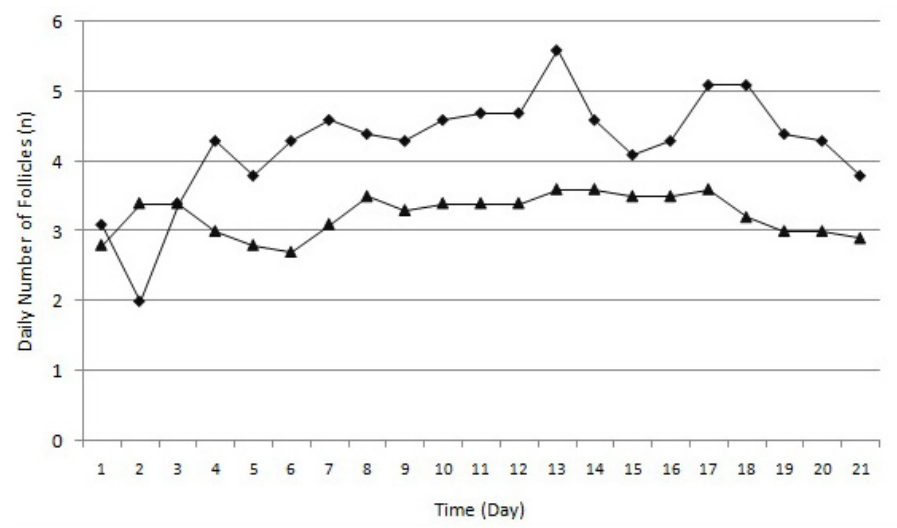

Figure 1d: Daily changes in the number of total follicles $(\geq 3.0 \mathrm{~mm}$ diameter) for 21 days in Gaddi goats during the breeding ( $\mathbf{m}$ ) and non-breeding seasons ( $\mathbf{\Delta})$.

None of the does exhibited estrus behavior and ovulation during NB season. Whereas, all does exhibited estrus signs after the second injection of Cloprostenol during $\mathrm{B}$ season. Average circulating concentrations of $\mathrm{P} 4$ during $\mathrm{NB}$ season was $0.30 \pm 0.04 \mathrm{ng} / \mathrm{mL}$ whereas during $B$ season average maximum concentration was much higher $(11.89 \pm 1.55 \mathrm{ng} / \mathrm{ml})$ which was recorded on Day 14 of estrous cycle. The last wave during B season was ovulatory, with interovulatory and interestrus interval of $20.85 \pm 0.63$ and $21.0 \pm 0.53$ days, respectively. Average (mean \pm SEM) diameter of ovulatory follicle $(6.85 \pm 0.24 \mathrm{~mm})$, mean luteal and follicular phase durations were $17.57 \pm 0.36$ and $3.14 \pm 0.26$ days, respectively. Similar pattern of lower progesterone concentration of $<1 \mathrm{ng} / \mathrm{ml}$ concentration were observed during $\mathrm{NB}$ season $(0.65$ $\mathrm{ng} / \mathrm{ml}$, Nogueira et al., 2015; $0.79 \mathrm{ng} / \mathrm{ml}$, Dogan 
et al., 2020). During B season variable higher P4 concentration $(12.4 \pm 2.1,13.3 \pm 1.7 \mathrm{ng} / \mathrm{ml})$ at Day 15 by (Sharma, 2015; Nogueira et al., 2015) and lower P4 concentration (7.68 \pm 0.46 , Dogan et al., 2020; 8.35 \pm 2.60 , Goel and Kharche, 2012; 9.16-10.95 ng/ $\mathrm{ml}$, Farshad et al., 2008) at Day 14 to 16 were also observed. Progesterone concentration of $<1 \mathrm{ng} / \mathrm{ml}$ throughout the NB season support our ultrasound investigations of non detection of corpus luteum in the present study. Progesterone concentrations are mediated by $\mathrm{LH}$ which plays an important role in follicular turnover during $\mathrm{B}$ season but not in the $\mathrm{NB}$ season. Increased day length during NB season is known to reduce the secretion of melatonin and to increase the negative feedback of oestradiol, which in turn inhibits the secretion of $\mathrm{GnRH}$ and results in reduced pulsatile LH secretion (Fatet et al., 2011). Similar observations (Farsi et al., 2018) suggesting the relationship of photoperiod and ambient temperature regarding the reproduction being activated in response to shorter photoperiod and lower ambient temperature, both of which were present during the $\mathrm{B}$ season in our study.

Average (mean \pm SEM) interovulatory interval recorded in present study was higher than Boer goats (19.7 \pm 0.2 , Nogueira et al., 2015), White Polish goats (20.4 \pm 1.1 ; Schwarz and Wierzchos, 2000), Saanen goats (20.47 \pm 0.19 ; Dogan et al., 2020), Najdi goats (20.6 \pm 0.89 ; Mohammadi et al., 2010), similar to Saanen goats $(20.8 \pm 0.89$; Menchaca and Rubianes, 2002; 20.7 \pm 1.0 ; Simoes et al., 2006), lower than Shiba goats (21.3 \pm 0.4 , Medan et al., 2005), respectively. Duration of estrous cycle observed in present study was slightly higher or similar to earlier reports of Boer goats (20.7 \pm 0.2 , Nogueira et al., 2015), Anglo-Nubian goats $(20.3 \pm 0.8$ and $22.8 \pm 1.3$ days), Serrana goats (20.4 \pm 1.1 days nulliparous; $21.0 \pm 0.7$, multiparous goats; Simoes et al., 2006).

\section{Conclusion and Recommendations}

Significantly higher number of follicular waves, number of follicles at wave emergence during second and third wave, shorter persistence of dominant follicle and early attainment of DF during first three waves with higher growth rate were observed during $B$ season. Whereas, significantly greater maximum diameter of DF and longer IWI between wave 2 and 3 was observed during NB season. Average mean P4 concentration was $0.30 \pm 0.04 \mathrm{ng} / \mathrm{ml}$ throughout the period of observation during $\mathrm{NB}$ whereas, peak $\mathrm{P} 4$ concentration of $11.89 \pm 1.55 \mathrm{ng} / \mathrm{ml}$ was observed at Day 14 of estrous cycle with interovulatory and interoestrus interval of $20.85 \pm 0.63$ and $21.0 \pm 0.53$ days during B season. Significant difference between average daily count of small and medium sized follicles along with average daily total number of visible follicles were observed during B season. Present study also supports the relationship of follicular development with progesterone concentration.

\section{Acknowledgement}

Authors acknowledge the financial assistance by Department of Dairy and Fisheries, GOI AdhocMisc 2127-37 project for carrying out this work.

\section{Authors Contribution}

Amit Sharma conducted the research trial, data collection, analysis and writing of manuscript. Dr. Pankaj Sood helped in conceptualizing the research. Both the authors contributed and coordinated in finalization of manuscript.

Conflict of interest

The authors have declared no conflict of interest.

\section{References}

Bartlewski, P.M., Beard, A.P., Cook, S.J., Chandolia, R.K., Honoramooz, A. and Rawlings, N.C., 1999. Ovarian antral follicular dynamics and their relationships with endocrine variables throughout the oestrous cycle in breeds of sheep differing in prolificacy. J. Reprod. Fert. 115: 111124. https://doi.org/10.1530/jrf.0.1150111

Cruz, J.F., Rondina, D. and Freitas, V.J.F., 2005. Ovarian follicular dynamics during anoestrus in Anglo Nubian and Saanen goats raised in tropical climate. Trop. Anim. Health Prod. 37: 395-402. https://doi.org/10.1007/s11250-0054166-6

de Castro, T., Rubianes, E.,Menchaca, A. and Rivero, A., 1999. Ovarian dynamics, serum estradiol and progesterone concentrations during the interovulatory interval in goats. Theriogenology. 52: 399-411. https://doi.org/10.1016/S0093691X(99)00138-7

Dogan,I.,Toker,M.B.,Alcay,S.and Udum Kucuksen, D., 2020. Comparison and assessment of ovarian 
follicular dynamics during the breeding and non-breeding season in Saanen goats. Vet. Med. Aust. 107: 63-71.

Farshad, A., Akhondzadeh, S., Zamiri, M.J. and Sadeghi, G.H., 2008. The estrous cycle of the Markhoz goat in Iran. Asian Aust. J. Anim. Sci. 21(10): 1411-1415. https://doi.org/10.5713/ ajas.2008.70707

Farsi, H., Mhani, M., Achaaban, M.R., Boukhliq, R., Tibary,A. and El-Allali, K.,2018. Environmental cues and seasonal patterns of reproduction in goats. Mor. J. Agro. Vet. Sci. 6(2): 158-167.

Fatet, A., Pellicer-Rubio, M.T. and Leboeuf, B., 2011. Reproductive cycle of goats. Anim. Reprod. Sci. 124: 211-219. https://doi.org/10.1016/j. anireprosci.2010.08.029

Ginther, O.J. and Kot, K., 1994. Follicular dynamics during the ovulatory season in goats. Theriogenology. 42: 987-1001. https://doi. org/10.1016/0093-691X(94)90121-X

Goel, A.K. and Kharche, S.D., 2012. Ovulatory pattern and serum progesterone levels during oestrous cycle in Jamunapari goats. Ind. J. Anim. Sci. 82 (5): 468-471.

Gonzalez de Bulnes, A., Santiago Moreno, J., Gomez-Brunet, A., Inskeep, E.K., Townsend, E.C. and Lopez-Sebastian, A., 1999. Follicular dynamics during the oestrous cycle in dairy goats. Anim.Sci.68: 547-554.https://doi.org/10.1017/ S1357729800050578

Gonzalez-Bulnes, A., Diaz-Delfa, C., Urrutia, B., Carrizosa, J.A. and Lopez-Sebastian, A., 2004. Ultrasonographic screening of ovulatory process in goats. Small Ruminant Res. 52: 165-168. https://doi.org/10.1016/S09214488(03)00231-1

Hunter, M.G., Robinson, R.S., Mann, G.E. and Webb, R., 2004. Endocrine and paracrine control of follicular development and ovulation rate in farm species. Anim. Reprod. Sci. 82-83: 461-477. https://doi.org/10.1016/j. anireprosci.2004.05.013

ICAR, 2013. Nutrient requirements of sheep, goats and rabbits. $3^{\text {rd }}$ ed. ICAR, New Delhi.

Medan, M.S., Watanabe, G., Sasaki, K., Groome, N.P., Sharawy, S. and Taya, K., 2005. Follicular and hormonal dynamics during the estrous cycle in goats. J. Reprod. Dev. 51: 455-463. https:// doi.org/10.1262/jrd.17017

Medan, M.S., Watanabe, G., Sasaki, K., Sharawy, S., Groome, N.P. and Taya, K., 2003. Ovarian dynamics and their associations with peripheral concentrations of gonadotropins, ovarian steroids, and inhibin during the estrous cycle in goats. Biol. Reprod. 69: 57-63. https://doi. org/10.1095/biolreprod.102.013334

Menchaca, A. and Rubianes, E., 2002. Relation between progesterone concentrations during the early luteal phase and follicular dynamics in goats. Theriogenology. 57: 1411-1419. https:// doi.org/10.1016/S0093-691X(02)00638-6

Mohammadi, G., Kohram, H., Gooraninejad, S., Yousefi, A. and Motaghedi, A., 2010. Ovarian follicular dynamics during the interovultaory interval in Najdi goats. Afr. J. Biotech. 9(32): 5236-5239.

Nogueira, D.M., Cavalieri, J., Gummow, B. and Parker, A.J., 2015. Comparison of follicular dynamics and hormone profiles in Boer goats examined during the breeding and non-breeding seasons in the tropics of Queensland, Australia. Small Ruminant Res. 125: 93-100. https://doi. org/10.1016/j.smallrumres.2015.02.014

$\mathrm{R}$ Core Team. 2013. R: A language and environment for statistical computing. $\mathrm{R}$ Foundation for Statistical Computing, Vienna, Austria.

Rubianes, E. and Menchaca, A., 2003. The pattern and manipulation of ovarian follicular growth in goats. Anim. Reprod. Sci. 78: 271-287. https:// doi.org/10.1016/S0378-4320(03)00095-2

Schwarz, T. and Wierzchos, E., 2000. Relationship between FSH and ovarian follicular dynamics in goats during the estrous cycle. Theriogenology. 53: 381.

Sharma, A. and Sood, P., 2019. Follicular dynamics in goats. Har. Vet. 58(S.I.): 1-7.

Sharma, S., 2015. Studies on estrous behavior and estrous cycle related endocrine profile of Gaddi Goats. M.V.Sc. thesis CSKHPKV Palampur, Himachal Pradesh, India.

Simoes, J., Almeida, J.C., Valentim, R., Baril, G., Azevedo, J., Fontes, P. and Mascarenhas, R., 2006. Follicular dynamics in Serrana goats. Anim. Reprod. Sci. 95: 16-26. https://doi. $\mathrm{org} / 10.1016 / \mathrm{j}$.anireprosci.2005.09.005

Vazquez, M.I., Forcada, F., Casao, A., Abecia, J.A., Sosa, C. and Palacin, I., 2010. Undernutrition and exogenous melatonin can affect the in vitro developmental competence of ovine oocytes on a seasonal basis. Reprod. Dom. Anim. 45: 677-684. https://doi.org/10.1111/j.14390531.2008.01329.x 